\title{
LY294002 prevents lipopolysaccharide-induced hepatitis in a murine model by suppressing IкB phosphorylation
}

\author{
ZHIZE CHEN, HUIMIN LIU, SHAOQIN LEI, BO ZHAO and ZHONGYUAN XIA \\ Department of Anesthesiology, Renmin Hospital of Wuhan University, Wuhan, Hubei 430060, P.R. China
}

Received August 26, 2014; Accepted July 3, 2015

DOI: $10.3892 / \mathrm{mmr} .2015 .4574$

\begin{abstract}
Although fulminant hepatitis represents a ubiquitous human health problem, there is a lack of effective therapeutic strategies that have few side-effects and the precise mechanisms underlying fulminant hepatitis are not fully understood. Phosphoinositide 3-kinase (PI3K) is a pivotal kinase known to regulate inflammatory responses in hepatic diseases. Although previous research indicates that PI3K is involved in cardiac diseases, including myocardial infarction, it currently remains unclear whether the inhibition of PI3K is essential for ameliorating the severity of lipopolysaccharide (LPS)-induced hepatitis. The aim of the present study was to investigate whether pharmacological blockade of PI3K ameliorates the development of LPS-induced murine acute hepatic injury. A murine model of LPS-induced acute hepatic injury was used to investigate the therapeutic effect of the pan-PI3K inhibitor, LY294002 on murine fulminant hepatitis and to investigate potential underlying mechanisms. The current report presents the in vivo role of LY294002 in protecting the mice from fulminant hepatitis. LY294002 was observed to exert significant protective effects on the liver by reducing the activities of alanine aminotransferase and aspartate aminotransferase, as well as by improving the histological architecture of the liver. In LPS-induced hepatitis, treatment with LY294002 clearly inhibited intrahepatic synthesis of various disease-relevant proinflammatory cytokines, including tumor necrosis factor- $\alpha$, interleukin (IL)- 6 , IL-1 $\beta$ and interferon- $\gamma$. Furthermore, LY294002 was observed to significantly inhibit IкB phosphorylation in LPS-injured mouse liver samples. Therefore, LY294002 may protect the liver from LPS-induced injury by inhibition of the IкB-nuclear factor $\kappa$-light-chain-enhancer of activated $\mathrm{B}$ cell dependent signaling pathway. Thus, the current report provides evidence that LY294002 exerts potent effects
\end{abstract}

Correspondence to: Dr Zhize Chen, Department of Anesthesiology, Renmin Hospital of Wuhan University, 99 Zhang Zhidong Road, Wuhan, Hubei 430060, P.R. China

E-mail: chenzhize2014@163.com

Key words: LY294002, lipopolysaccharide, acute hepatitis, ІкB phosphorylation against LPS-induced hepatic injury, indicating its potential therapeutic value for the treatment of acute hepatitis.

\section{Introduction}

Hepatic injury, caused by misdirected immune stimulation or viral infection, is a type of acute inflammatory injury characterized by inflammatory infiltration of macrophages, $\mathrm{T}$ cells, and neutrophils into liver (1). Although hepatitis represents a ubiquitous human health problem, effective therapeutic strategies with minimal side-effects are lacking and the precise mechanisms underlying hepatitis are not fully understood. There are various mouse models of inflammatory liver injury, which have been established to facilitate functional studies on the mechanisms of hepatic injury. For example, liver failure, induced by either intravenous injection of concanavalin A or by sensitizing mice with D-galactosamine, prior to lipopolysaccharide (LPS) administration, is commonly used as an experimental animal model for mimicking human liver disease $(2,3)$. Liver failure is characterized by an accumulation and activation of macrophages, which are highlighted for being involved in the inflammation process by producing large quantities of tumor necrosis factor (TNF)- $\alpha$, which leads to a direct hepatotoxic potential $(4,5)$. In addition, TNF is known to mediate intrahepatic induction of inducible NO synthase, which is also significant in acute hepatitis (6).

Inflammation is a pathological condition in which various signaling mechanisms control a complex network of cellular and molecular interactions involving the crosstalk between independent biochemical cascades, which terminate in the activation of gene expression programs for cytokines and chemokines (7). In the canonical pathway, nuclear factor $\kappa$-light-chain-enhancer of activated B cell (NF- $\kappa B$ ) is present as a latent, inactive I $\mathrm{KB}$-bound complex in the cytoplasm, which prevents it from entering nuclei. When these cells are exposed to stimuli, including LPS, LPS binds to Toll-like receptor- 4 and phosphorylates $\mathrm{I} \mathrm{B} B$, resulting in its subsequent degradation, which enables NF- $\kappa \mathrm{B}$ to be released from I $\mathrm{B}$ and enter the nucleus (8). Numerous stimuli activate NF- $\kappa B$, including LPS, TNF- $\alpha$ and interleukin (IL)-1, and other physiological and pathological stimuli $(9,10)$. IкB phosphorylation regulates the expression of numerous genes involved in inflammatory responses, including genes encoding proinflammatory cytokines, chemokines, enzymes that generate mediators of inflammation, immune receptors and adhesion molecules (11). 
Phosphoinositide 3-kinase (PI3K) is a pivotal kinase known to regulate inflammatory responses in various types of disease $(12,13)$. In recent years, there has been increasing evidence regarding the pan-PI3K inhibitor, LY294002 ameliorating the severity of a series of models of autoimmune diseases, including cecal ligation and puncture-induced sepsis, idiopathic pulmonary fibrosis and colitis-induced cancer (14-16). However, whether the PI3K inhibitor suppresses autoimmune hepatitis remains unclear. Furthermore, pan-PI3K inhibition may promote infarct resorption and prevents adverse cardiac remodeling following myocardial infarction in mice (17). A study using $\mathrm{PI} 3 \mathrm{~K} \gamma$ deficient mice demonstrated a complex contribution of PI3K $\gamma$ to reparative angiogenesis in myocardial infarction (18). Although previous research suggested that PI3K $\gamma$ inhibitors, such as AS605240, were involved in liver diseases (19), it remains unclear whether pan-PI3K inhibition is essential for ameliorating the severity of LPS-induced hepatitis. In the present study, the therapeutic effect of the pan-PI3K inhibitor, LY294002 on acute hepatitis was investigated using an LPS-induced murine hepatitis model. Our results showed that LY294002 prevented the development of hepatitis stimulated by LPS. These data may define an anti-inflammatory role of LY294002 in immunologically mediated hepatic diseases and may provide a foundation for a novel therapeutic modality for treatment of inflammatory hepatic diseases.

\section{Materials and methods}

Reagent and animals. A total of 80 female BALB/c mice (aged, 6-8 weeks) were obtained from Hua Fukang Experimental Animal Center (Bejing, China) and treated with humane care according to the National Institutes of Health Guidelines of China. The mice were housed (five mice per cage) at $23+2^{\circ} \mathrm{C}$ under a 12:12 light/dark cycle and allowed free access to food and water. Following an acclimatization period of 1 week, they were divided into four groups, according to body weight. The pan-PI3K inhibitor, LY294002 (Fig. 1) was purchased from Sigma Aldrich (St. Louis, MO, USA).

Establishment of a murine model of LPS-induced hepatitis. Thhe present study was approved by the ethics committee of Renmin hospital of Wuhan university (Wuhan, China). LPS dissolved in saline was administered at a total volume of $100 \mu \mathrm{l}$ per mouse via i.p. injection. For therapeutic agent treatment, LY294002 (concentration, $40 \mu \mathrm{M}$; volume, $10 \mu \mathrm{l}$ ) was administered once by i.p. injection $1 \mathrm{~h}$ prior to treatment with the corresponding hepatotoxin in the murine model of LPS-induced hepatitis. Following anesthetization of the mice with $45 \mathrm{mg} / \mathrm{kg}$ ketamine (Sigma-Aldrich), serum and liver tissue samples were collected $8 \mathrm{~h}$ following LPS treatment. To examine survival rate, the mice were challenged with LPS, however the mice were pretreated with LY294002 $1 \mathrm{~h}$ prior to LPS treatment. The mice were subsequently monitored every $2 \mathrm{~h}$ for survival.

Analysis of liver enzymes. Liver injury in LPS-induced acute hepatitis was quantified by measurement of the serum enzyme activities of alanine aminotransferase (ALT) and aspartate

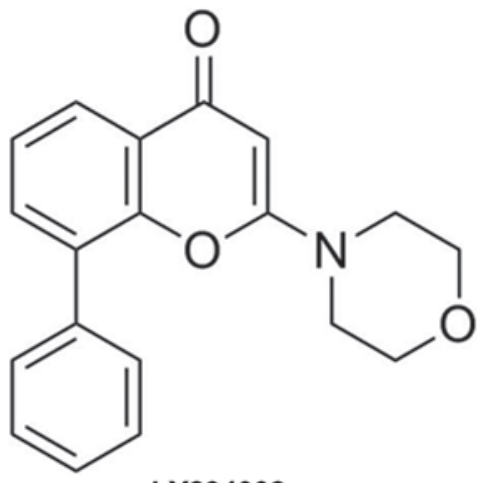

LY294002

Figure 1. Molecular formula of LY294002.

aminotransferase (AST) using an automated procedure with an enzymatic assay (ALT-ASTl Kainos Laboratories, Toyko, Japan).

Histologic examination. Four weeks after immunization, the mice were sacrificed by anesthetization, and their hearts were perfused with normal saline, removed, fixed in $4 \%$ buffered formaldehyde (BASO, Taiwan, China), and processed for hematoxylin and eosin (H\&E) staining (BASO). Hepatic injury on LPS-induced acute hepatitis was scored on the H\&E-stained sections using grades from 0 to 4 as follows: 0 , No necrotic infiltrates; 1 , small foci of necrotic cells between hepatocytes or necrotic cells surrounding individual hepatocytes; 2 , larger foci of 100 necrotic cells or involving 30 hepatocytes; $3,10 \%$ of a hepatocytic cross-section involved; and $4,30 \%$ of a hepatic cross-section involved $(20,21)$.

ELISA. The concentrations of TNF- $\alpha$, IL- $1 \beta$, IFN- $\gamma$ and IL-6 in plasma samples or lymph node cell suspensions were analyzed by ELISA using commercially available TNF- $\alpha$ (cat. no. F8005A), IL-1 $\beta$ (cat. no. F10091A), IFN- $\gamma$ (cat. no. F5980A) and IL-6 (cat. no. F7699A) ELISA kits from JingMei Biotech. (Shenzhen, China), according to the manufacturer's instructions.

Western blot analysis. The mice were pre-treated with LY294002 (concentration, $40 \mu \mathrm{M}$; volume, $10 \mu \mathrm{l}$ ) $1 \mathrm{~h}$ before stimulation with LPS, respectively, for $15,30,60$ or $90 \mathrm{~min}$. The mice were then sacrificed at different time points $(15,30,60$ or $90 \mathrm{~min})$ to harvest the liver tissues. Protein $(20 \mu \mathrm{g})$ from each sample was mixed with an equal volume of $2 \mathrm{X}$ SDS sample buffer (Beyotime Institute of Biotechnology, Haimen, China), boiled for $5 \mathrm{~min}$ and then separated by $10 \%$ SDS-polyacrylamide gel electrophoresis. Following electrophoresis, proteins were transferred to polyvinylidene fluoride membranes (EMD, Millipore, Billerica, MA, USA). The membranes were incubated with monoclonal rabbit anti-IкB antibody (cat. no. ab32518; 1:1,000; Abcam, Cambridge, MA, USA), monoclonal mouse anti-phosphorylated (p)-IкB antibody (cat. no. ab12135; 1: 1,000; Abcam) or monoclonal mouse anti-GAPDH antibody (cat. no. G9295; 1:50,000; Sigma-Aldrich) at $4^{\circ} \mathrm{C}$ overnight. The total I $\mathrm{KB}$ and $\mathrm{p}$-I $\kappa \mathrm{B}$ protein signal was quantified by scanning densitometry using a Quantity One image analysis system (version 4.6.2; Bio-Rad Laboratories, Inc., Hercules, CA, USA). 
A

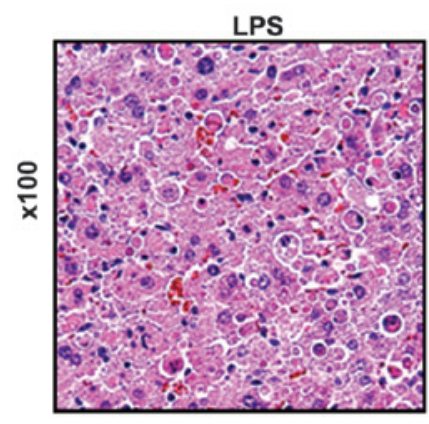

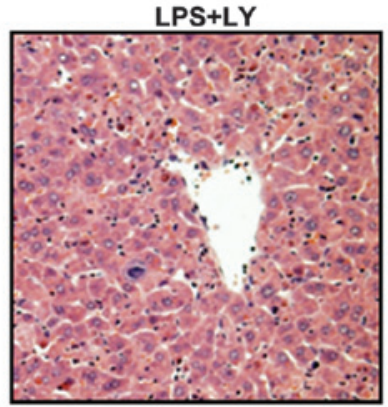

C

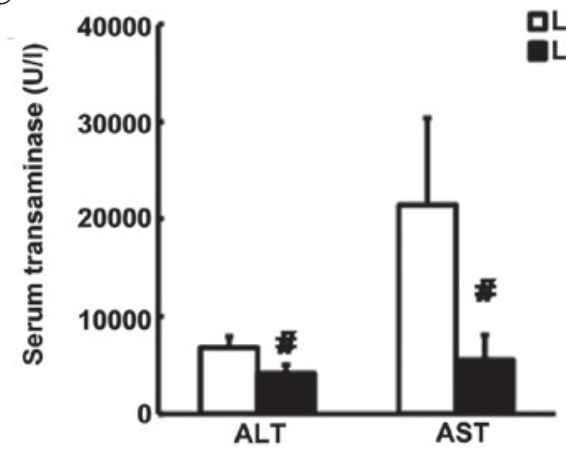

D
B

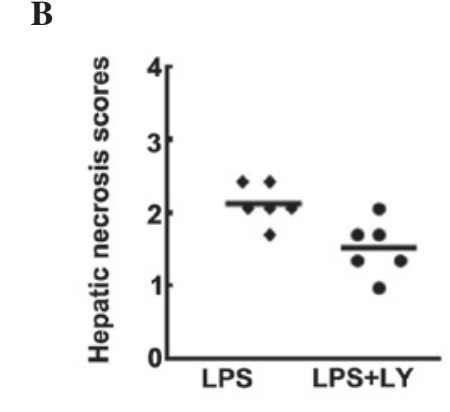

LLS LY

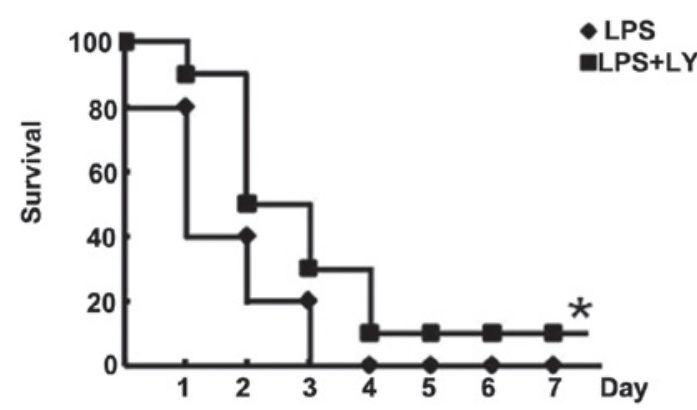

Figure 2. (A) Representative liver histology of mice from each group. Liver sections were stained with hematoxylin and eosin (original magnification, x100). (B) Centrilobular necrosis scores. The histological score of centrilobular necrosis for each mouse ( $\mathrm{n}=5$ ) $8 \mathrm{~h}$ following LPS injection is presented. Histology slides were evaluated by a board-certified veterinary pathologist blinded to the treatment groups. Histopathological changes were recorded and graded on a severity scale of 0 to 4 ( 0 , no necrotic infiltrates; 1 , small foci of necrotic cells between hepatocytes, or necrotic cells surrounding individual hepatocytes; 2, larger foci of 100 necrotic cells or involving 30 hepatocytes; $3,10 \%$ of hepatic cross-section involved; 4 , 30\% of a hepatic crosss-section involved). 'Saline + LPS; •LY + LPS. (C) Survival curve of mice following administration of LPS. Balb/c mice (n=6) were administrated with saline or LY294002 1 h before and $8 \mathrm{~h}$ after a lethal intraperitoneal dose of LPS. Animals were monitored over a 7 day period for survival. Data is plotted as the percentage of animals surviving. Saline + LPS; LY294002+LPS (D) Survival curve of mice following administration of LPS. BALB/c mice (n=5) were administrated with saline or LY $1 \mathrm{~h}$ prior to and $8 \mathrm{~h}$ following a lethal intraperitoneal dose of LPS. Mice were monitored over a seven-day period for survival. Data are plotted as the percentage of surviving mice. ${ }^{*} \mathrm{P}<0.05$ and ${ }^{\#} \mathrm{P}<0.01$. LPS, lipopolysaccharide; ALT, alanine aminotransferase; AST, aspartate aminotransferase; LY, LY294002.

Statistical analysis. The Mann-Whitney U test was used for evaluation of the severity scores. Parametric data were statistically analyzed by Student's t-test or one-way analysis of variance. Data are presented as means \pm standard deviation and $\mathrm{P}<0.05$ was considered to indicate a statistically significant difference.

\section{Results}

LY294002 administration exerts therapeutic effects in a mouse model of LPS-induced acute hepatic injury. Injection of LPS causes hepatic injury, including hepatic necrosis, steatosis and inflammatory infiltration. To estimate the efficacy of LY294002 treatment on acute hepatic liver injury, mice were sacrificed $8 \mathrm{~h}$ following an i.p. injection of LPS. Routine histopathology confirmed hepatic injury had been achieved in the murine model of LPS-induced acute hepatitis. Furthermore, the mice treated with LY294002 demonstrated a markedly reduced severity of hepatic necrosis when compared with the LPS-treated mice (Fig. 2A). The pattern of infiltrate was assessed by scoring of H\&E stained sections. Treatment with LY294002 significantly alleviated LPS-induced hepatitis in mice, as indicated by the reduction of hepatic necrosis. The histological scores of inflammatory infiltrates for individual mice are presented in Fig. 2B. LY294002 treatment significantly reduced the LPS-induced histopathological hepatic injury in mice $(\mathrm{P}<0.05)$. Therefore, treatment with LY294002 significantly alleviated LPS-induced liver injury in mice, as indicated by the reduction of serum aminotransferase (Fig. 2C; $\mathrm{P}<0.01$ ). Furthermore, reduction in liver enzyme levels by LY294002 treatment correlated with enhanced survival. This protective effect of LY294002 pretreatment was further confirmed by analysis of the survival rate of mice challenged with LPS. Mortality was observed as early as $2 \mathrm{~h}$ following LPS administration. However, animals treated with LY294002 showed a statistically significant enhancement in survival rate $(\mathrm{P}<0.05$; Fig. $2 \mathrm{D})$.

Pan-PI3K inhibitor, LY294002 reduces the production of proinflammatory cytokines. Proinflammatory cytokines are important in human and animal models of acute liver injury (22). In the present study, the effects of pan-PI3K inhibitor, LY294002 on proinflammatory cytokines in LPS-induced acute hepatitis were analyzed. As shown in Fig. 3A-D, mice injected with LPS demonstrated increased secretion levels of TNF- $\alpha$, IL-6, IL- $1 \beta$ and IFN- $\gamma$ in murine liver tissue. Administration of LY294002 in mice following LPS injection resulted in a significant reduction of TNF- $\alpha$, IL-6, IL-1 $\beta$ and IFN- $\gamma$ production (Fig. 3A-D; $\mathrm{P}<0.05$ ). These results indicate that LY294002 treatment suppresses the production of cytokines during inflammation, which may protect the liver from injury. 
A

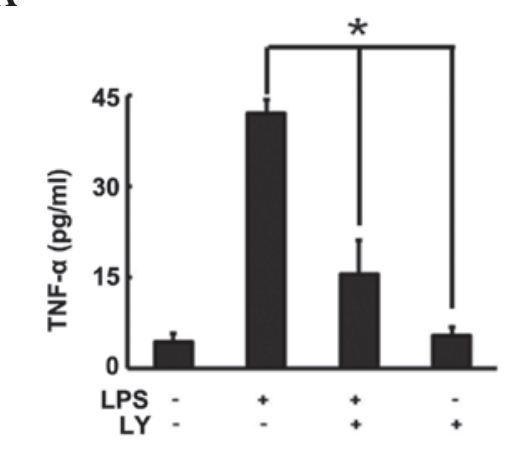

C

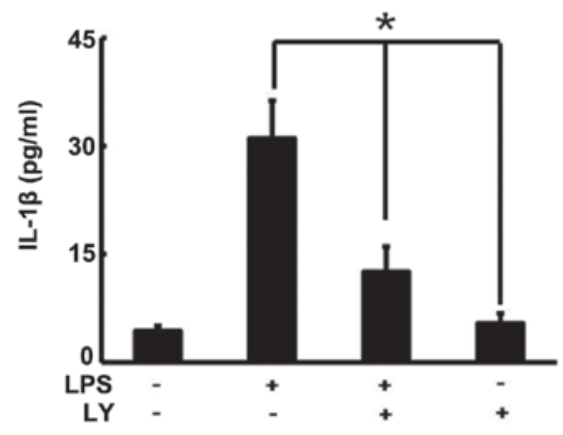

B

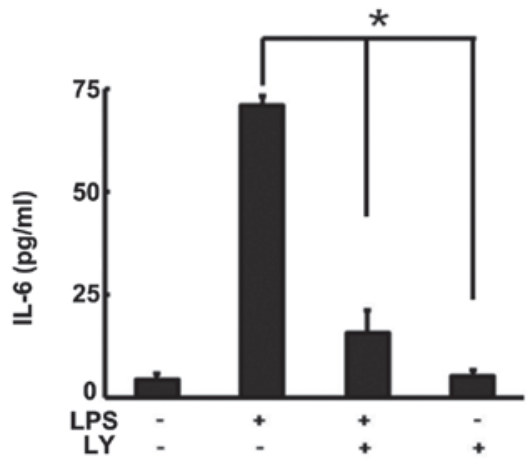

D

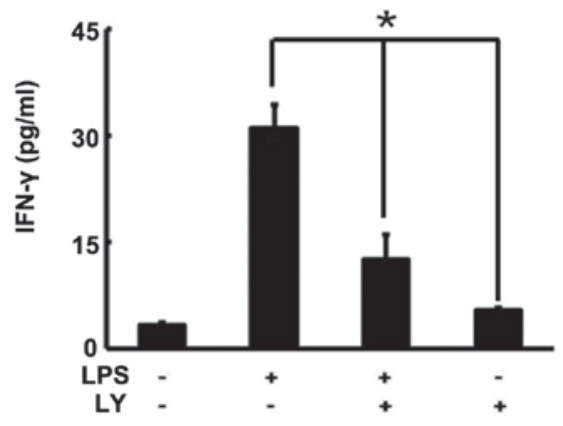

Figure 3. Dose-effect influence of LY on TNF- $\alpha$, IL-6, IL-1 $\beta$ and IFN- $\gamma$ levels in the liver tissue of mice exhibiting LPS-induced acute hepatic injury. ELISA analysis of (A) TNF- $\alpha$, (B) IL-6, (C) IL-1 $\beta$ and (D) IFN- $\gamma$ from the livers of mice from the different treatment groups (n=5 per group). Data are presented as means + standard deviation. "P<0.05 vs. LPS. LY, LY294002; TNF, tumor necrosis factor; IL, interleukin; IFN, interferon; LPS, lipopolysaccharide.
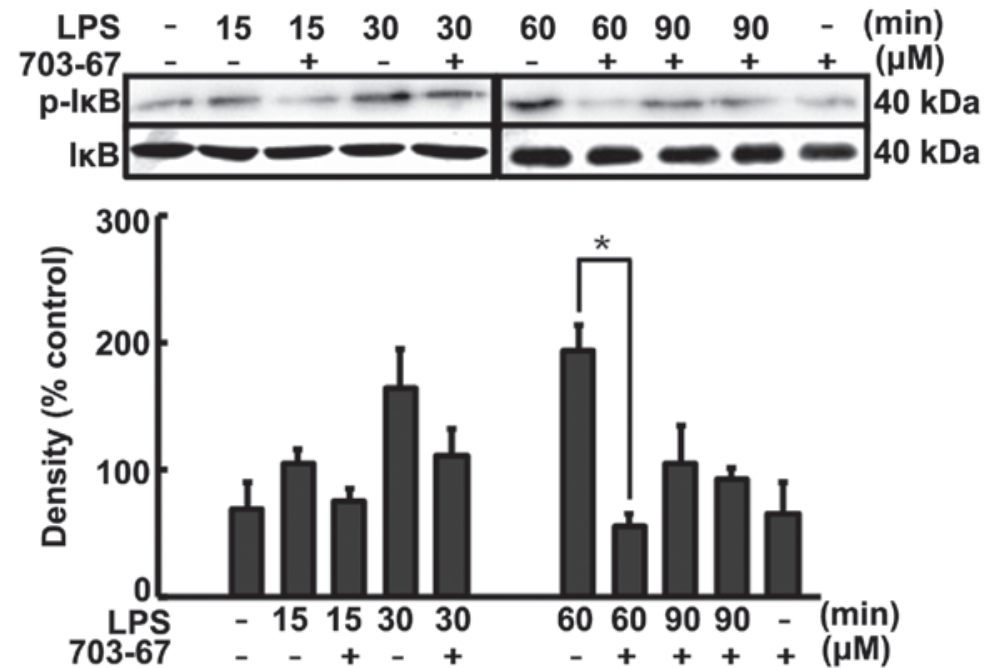

Figure 4. Western blot analysis of hepatic phosphorylated IкB. The mice were pre-treated with LY (concentration, $40 \mu \mathrm{M}$; volume, $10 \mu \mathrm{l}$ ) $1 \mathrm{~h}$ before stimulation with LPS for 15, 30, 60 or $90 \mathrm{~min}$. Western blot analysis determined the level of IкB phosphorylation from 15 to 90 min following LPS-injection. Mice were injected with LPS $1 \mathrm{~h}$ after LY administration, and were sacrificed $8 \mathrm{~h}$ later. One of three representative experiments is presented. "P $<0.05$. LPS, lipopolysaccharide; LY, LY294002; p, phosphorylated.

LY294002 treatment inhibits IאB phosphorylation following $L P S$ injection. Phosphorylation of the inhibitory protein, ІкB enables nuclear translocation and DNA binding of NF-kB during inflammation (23). To gain further insight into the mechanism of LY294002-mediated regulation of inflammation, variation in I $\mathrm{kB}$ phosphorylation in the mouse model of LPS-induced hepatitis was analyzed in the present study. As shown in Fig. 4, LY294002 significantly inhibited IкB phosphorylation in the mouse model. The mice were pre-treated with LY294002 (concentration, $40 \mu \mathrm{M}$; volume, $10 \mu \mathrm{l}$ ) $1 \mathrm{~h}$ before stimulation with LPS, respectively, for 15, 30, 60 or $90 \mathrm{~min}$. Subsequently, it was observed that LY294002 inhibited I $\kappa$ B phosphorylation from 15 to 90 min following LPS-injection. The difference was statistically significant at 60 min following LPS-injection (Fig. 4; $\mathrm{P}<0.05$ ).

Toxicity of LY294002. To examine the toxicity of LY294002, the mice were sacrificed following 4 weeks of daily injections 

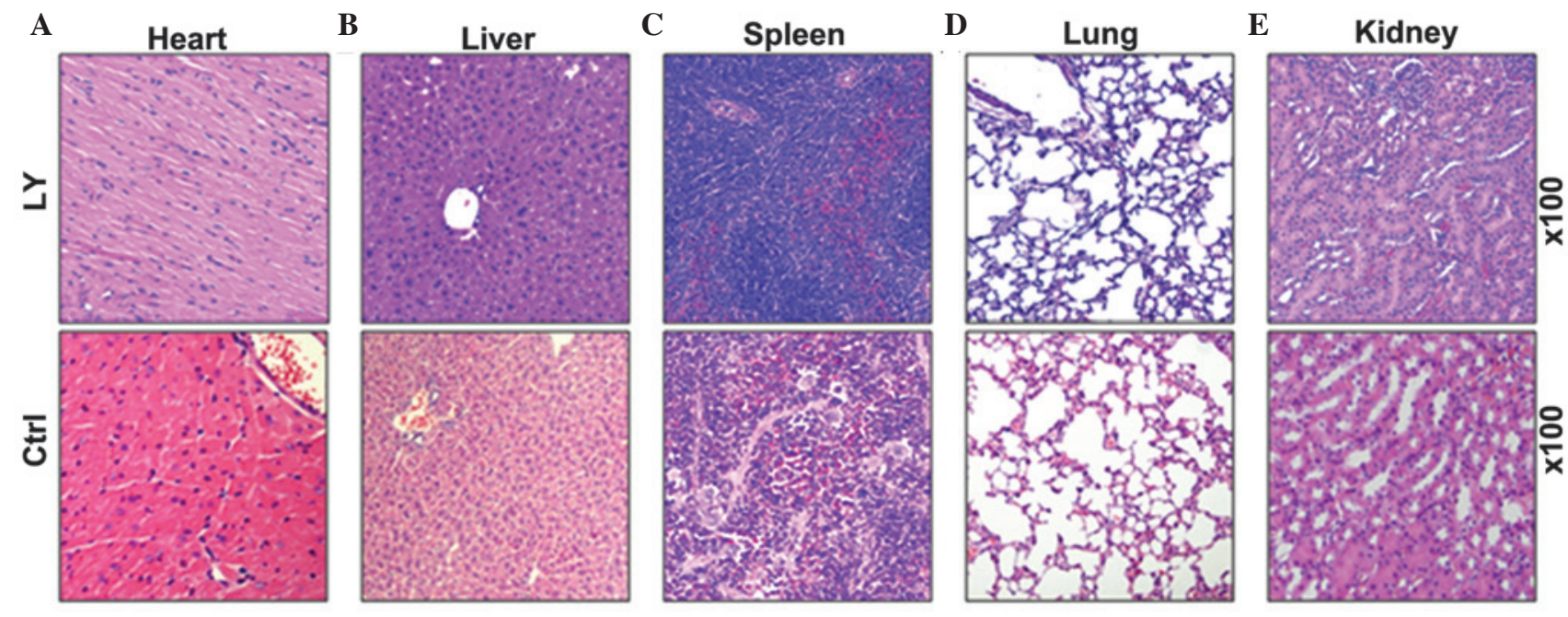

Figure 5. Representative liver histology of mice. LY294002 (concentration, $40 \mu \mathrm{M}$; volume, $10 \mu 1$ ) was injected intraperitoneally into BALB/c mice once per day for 4 weeks. Representative histological sections from the (A) heart, (B) liver, (C) spleen, (D) lung and (E) kidney tissue were stained with hematoxylin and eosin (original magnification, x100). Ctrl, control; LY, LY294002 treatment.

of LY294002 (concentration, $40 \mu \mathrm{M}$; volume, $10 \mu \mathrm{l}$ ) and histopathological analysis of heart, liver, spleen, lung and kidney tissue was performed. As shown in Fig. 5, no significant difference was observed in the histopathology between the LY294001 and the normal control groups (Fig. 5).

\section{Discussion}

The current report demonstrates the in vivo role of LY294002 in protecting mice from fulminant hepatitis and investigates the possible underlying mechanisms. In the present report, LY294002 was observed to protect the liver from injury by reducing the activities of ALT and AST, and by improving the histological architecture of the liver. In the mouse model of LPS-induced hepatitis, treatment of LY294002 markedly inhibited intrahepatic synthesis of various disease-relevant proinflammatory cytokines (TNF- $\alpha$, IL-6, IL- $1 \beta$ and IFN- $\gamma$ ). Furthermore, LY294002 significantly inhibited IкB phosphorylation in the mouse model of LPS-induced hepatitis. Therefore, it was hypothesized that LY294002 may protect the liver from LPS-induced injury by inhibition of the I $\kappa \mathrm{B}-\mathrm{NF}-\kappa \mathrm{B}$ dependent signaling pathway.

As a ubiquitous transcription factor that regulates various genes involved in inflammation and immune responses, NF- $\mathrm{KB}$ is normally sequestered in the cytoplasm where it associates with a family of inhibitory proteins, known as IкB (24). In response to external signals, IкB is phosphorylated by the IкB kinase complex, and subsequently degraded through ubiquitin-dependent proteolysis (25). Notably, in the present study, LY294002 administration was observed to decrease the cytoplasmic level of I $\mathrm{I} B$ protein in sections of mouse liver tissue following LPS injection. These data indicate that LY294002 may bind to IкB and, therefore, may be involved

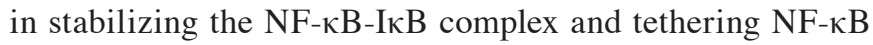
in the cytosol. Thus, establishing whether LY294002 binds to I $\mathrm{B}$ during LPS-induced NF- $\mathrm{BB}$ activation may be significant. In our future studies, the focus will be on the mechanism by

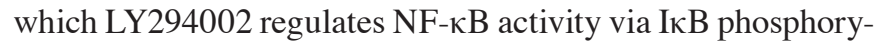
lation inhibition.
Proinflammatory cytokines are critical in the process of inflammation, and the increased production of TNF- $\alpha$, IL-6, IL-1 $\beta$ and IFN- $\gamma$ has previously been reported to be associated with autoimmune cardiac diseases (26-28). In the current study, injection with LPS resulted in marked intrahepatic increases of TNF- $\alpha$, IL-6, IL- $1 \beta$ and IFN- $\gamma$, which was consistent with previous reports (29). Subsequent LY294002 treatment clearly inhibited the serum protein levels of TNF- $\alpha$, IL- 6 , IL-1 $\beta$ and IFN- $\gamma$; the T cell-produced cytokines in LPS-injected mice. The results indicate that LY294002 may protect mice from LPS-induced acute hepatic injury by inhibition of proinflammatory cytokines.

The PI3K/AKT signaling pathway has been shown to be involved in LPS-induced immune cell proliferation, accumulation in the liver and consequently liver damage $(30,31)$. In addition, the activation of PI3K/AKT signaling is key in various autoimmune, inflammatory and allergic processes (32-34). The pan-PI3K inhibitor, LY294002 has demonstrated its favorable anti-inflammatory effects in murine models of certain inflammatory diseases via selectively prohibiting activation of the PI3K/AKT signaling pathway in various immune cell types, which was reflected by the reduction of chemokine-induced AKT phosphorylation in immunological cells following LY294002 treatment $(35,36)$. The present study confirmed that LY294002 effectively mediates the induction and development of LPS-induced hepatitis, which was accompanied by a significant reduction in histopathological hepatic necrosis.

In conclusion, the present study demonstrated the hepatoprotective activity of the compound, LY294002 in a mouse model of LPS-induced liver injury, resembling autoimmune hepatitis. The present study demonstrates that the pan-PI3K inhibitor,LY294002 effectively protects and treats LPS-induced murine hepatitis by targeting PI3K activity and consequently suppressing leukocyte infiltration, as well as immunoregulating the unbalance between pro- and anti-inflammation. The major mechanism of this hepatoprotective efficacy appears to be the inhibition of intrahepatic IкB phosphorylation, which prevents the subsequent synthesis of TNF- $\alpha$, IL-6, IL-1 $\beta$ and IFN- $\gamma$. The findings of the present study may be significant in 
the development of LY294002 as a therapeutic agent for the prevention and treatment of human myocarditis. Consequently, the present study provides a novel insight into the treatment of inflammatory liver diseases, such as autoimmune hepatitis. However, further preclinical and clinical studies using a PI3K inhibition compound, such as LY294002, are required and may be valuable towards the treatment of hepatic injury.

\section{Acknowledgements}

The present study was supported by Wuhan Science and Technology, Wuhan, China (grant no. 2013062301010818).

\section{References}

1. Friedman SL: Molecular regulation of hepatic fibrosis, an integrated cellular response to tissue injury. J Biol Chem 275: 2247-2250, 2000.

2. Tiegs G, Hentschel J and Wendel A: A T cell-dependent experimental liver injury in mice inducible by concanavalin A. J Clin Invest 90: 196-203, 1992.

3. Moebius U, Manns M, Hess G, Kober G, Meyer zum Büschenfelde KH and Meuer SC: T cell receptor gene rearrangements of $\mathrm{T}$ lymphocytes infiltrating the liver in chronic active hepatitis B and primary biliary cirrhosis (PBC): Oligoclonality of PBC-derived T cell clones. Eur J Immunol 20: 889-896, 1990.

4. Schumann J,WolfD,PahlA,BruneK,PapadopoulosT,vanRooijen N and Tiegs G: Importance of Kupffer cells for T-cell-dependent liver injury in mice. Am J Pathol 157: 1671-1683, 2000.

5. Gantner F, Leist M, Lohse AW, Germann PG and Tiegs G: Concanavalin A-induced T-cell-mediated hepatic injury in mice: The role of tumor necrosis factor. Hepatology 21: 190-198, 1995.

6. Koerber K, Sass G, Kiemer AK, Vollmar AM and Tiegs G: In vivo regulation of inducible NO synthase in immune-mediated liver injury in mice. Hepatology 36: 1061-1069, 2002.

7. Duran A, Rodriguez A, Martin P, Serrano M, Flores JM, Leitges M, Diaz-Meco MT and Moscat J: Crosstalk between PKCzeta and the IL4/Stat6 pathway during T-cell-mediated hepatitis. EMBO J 23 : 4595-4605, 2004.

8. Siebenlist U, Franzoso G and Brown K: Structure, regulation and function of NF-kappa B. Annu Rev Cell Biol 10: 405-455, 1994.

9. Baeuerle PA and Baltimore D: NF-kappa B: Ten years after. Cell 87: 13-20, 1996.

10. Cimino F, Esposito F, Ammendola R and Russo T: Gene regulation by reactive oxygen species. Curr Top Cell Regul 35: 123-148, 1997.

11. Wright FL, Moore EE, Nydam TL, et al: QS406. Hypertonic saline inhibits pro-inflammatory effects of cytokine stimulation on pulmonary epithelium at the common pathway of IKB phosphorylation. J Surg Res 144: 429, 2008.

12. Ruckle T, Schwarz MK and Rommel C: PI3Kgamma inhibition: Towards an 'aspirin of the 21st century'? Nat Rev Drug Discov 5: 903-918, 2006.

13. Peng XD, Wu XH, Chen LJ, Wang ZL, Hu XH, Song LF, He CM, Luo YF, Chen ZZ, Jin K, et al: Inhibition of phosphoinositide 3 -kinase ameliorates dextran sodium sulfate-induced colitis in mice. J Pharmacol Exp Ther 332: 46-56, 2010.

14. Kim HS, Park EJ, Park SW, Kim HJ and Chang KC: A tetrahydroisoquinoline alkaloid THI-28 reduces LPS-induced HMGB1 and diminishes organ injury in septic mice through p38 and $\mathrm{PI} 3 \mathrm{~K} / \mathrm{Nrf2} / \mathrm{HO}-1$ signals. Int Immunopharmacol 17: 684-692, 2013.

15. Stahl M,SchuppJ,JägerB,SchmidM,ZisselG,Müller-Quernheim J and Prasse A: Lung collagens perpetuate pulmonary fibrosis via CD204 and M2 macrophage activation. Plos One 8: e81382, 2013.

16. Khan MW, Keshavarzian A, Gounaris E, Melson JE, Cheon EC Blatner NR, Chen ZE, Tsai FN, Lee G, Ryu H, et al: PI3K/AKT signaling is essential for communication between tissue-infiltrating mast cells, macrophages and epithelial cells in colitis-induced cancer. Clin Cancer Res 19: 2342-2354, 2013.

17. Seropian IM, Abbate A, Toldo S, Harrington J, Smithson L, Ockaili R, Mezzaroma E, Damilano F, Hirsch E and Van Tassell BW: Pharmacologic inhibition of phosphoinositide 3-Kinase gamma (PI3K $\gamma$ ) promotes infarct resorption and prevents adverse cardiac remodeling after myocardial infarction in mice. J Cardiovasc Pharmacol 56: 651-658, 2010.
18. Siragusa M, Katare R, Meloni M, Damilano F, Hirsch E, Emanueli C and Madeddu P: Involvement of phosphoinositide 3-kinase gamma in angiogenesis and healing of experimental myocardial infarction in mice. Circ Res 106: 757-768, 2010.

19. Wang ZL, Wu XH, Song LF, Wang YS, Hu XH, Luo YF, Chen ZZ, Ke J, Peng XD, He CM, et al: Phosphoinositide 3-kinase gamma inhibitor ameliorates concanavalin A-induced hepatic injury in mice. Biochem Biophys Res Commun 386: 569-574, 2009.

20. Rangachari M, Mauermann N, Marty RR, Dirnhofer S, Kurrer MO, Komnenovic V, Penninger JM and Eriksson U: T-bet negatively regulates autoimmune myocarditis by suppressing local production of interleukin 17. J Exp Med 203: 2009-2019, 2006.

21. Eriksson U, Ricci R, Hunziker L, Kurrer MO, Oudit GY, Watts TH, Sonderegger I, Bachmaier K, Kopf M and Penninger JM: Dendritic cell-induced autoimmune heart failure requires cooperation between adaptive and innate immunity. Nat Med 9: 1484-1490, 2003.

22. Affò S, Morales-Ibanez O, Rodrigo-Torres D, Altamirano J, Blaya D, Dapito DH, Millán C, Coll M, Caviglia JM, Arroyo V, et al: CCL20 mediates lipopolysaccharide induced liver injury and is a potential driver of inflammation and fibrosis in alcoholic hepatitis. Gut 63: 1782-1792, 2014.

23. Bao XQ and Liu GT: Induction of overexpression of the 27- and 70-kDa heat shock proteins by bicyclol attenuates concanavalin A-Induced liver injury through suppression of nuclear factor-kappaB in mice. Mol Pharmacol 75: 1180-1188, 2009.

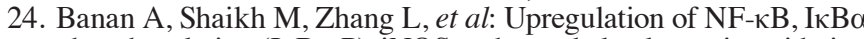
phosphorylation (I $\mathrm{I} \mathrm{B} \alpha . \mathrm{P})$, iNOS and cytoskeletal protein oxidation and dysfunction in colonic mucosa of patients with inflammatory bowel disease (IBD). Gastroenterology 124: A198, 2003.

25. Yamaoka S, Courtois G, Bessia C, Whiteside ST, Weil R, Agou F, Kirk HE, Kay RJ and Israël A: Complementation cloning of NEMO, a component of the IkappaB kinase complex essential for NF-kappaB activation. Cell 93: 1231-1240, 1998.

26. Xie JH, Yamniuk AP, Borowski V, Kuhn R, Susulic V, Rex-Rabe S, Yang X, Zhou X, Zhang Y, Gillooly K, et al: Engineering of a novel anti-CD40L domain antibody for treatment of autoimmune diseases. J Immunol 192: 4083-4092, 2014.

27. Watanabe R, Azuma RW, Suzuki J, Ogawa M, Itai A, Hirata Y, Komuro I and Isobe M: Inhibition of NF- $\mathrm{\kappa B}$ activation by a novel IKK inhibitor reduces the severity of experimental autoimmune myocarditis via suppression of T-cell activation. Am J Physiol Heart Circ Physiol 305: H1761-H1771, 2013.

28. Dinarello CA, Simon A and van der Meer JW: Treating inflammation by blocking interleukin-1 in a broad spectrum of diseases. Nat Rev Drug Discov 11: 633-652, 2012.

29. Knulst AC, Tibbe GJ, Bril-Bazuin C, Breedland EG, van Oudenarena, Benner R and Savelkoul HF: Cytokine detection and modulation in acute graft vs. host disease in mice. Mediators Inflamm 3: 33-40, 1994.

30. Van de Laar L, Buitenhuis M, Wensveen FM, Janssen HL, Coffer PJ and Woltman AM: Human CD34-derived myeloid dendritic cell development requires intact phosphatidylinositol 3-kinase-protein kinase B-mammalian target of rapamycin signaling. J Immunol 184: 6600-6611, 2010.

31. Rao J, Qian X, Li G, Pan X, Zhang C, Zhang F, Zhai Y, X and Lu L: ATF3-mediated NRF2/HO-1 signaling regulates TLR4 innate immune responses in mouse liver ischemia/reperfusion injury. Am J Transplant 15: 76-87, 2015.

32. Yoo SY, Le TK, Jeong JJ and Kim DH: Poligapolide, a PI3K/Akt inhibitor in immunodeficiency virus type 1 TAT-transduced CHME5 cells, isolated from the rhizome of Polygala tenuifolia. Chem Pharm Bull (Tokyo) 62: 467-471, 2014.

33. Liu SQ, Jiang S, Li C,Zhang B and Li QJ: miR-17-92 cluster targets phosphatase and tensin homology and ikaros family zinc finger 4 to promote TH17-mediated inflammation. J Biol Chem 289: 12446-12456, 2014.

34. Goodwin CB, Li XJ, Mali RS, Chan G, Kang M, Liu Z, Vanhaesebroeck B, Neel BG, Loh ML, Lannutti BJ, et al: PI3K p1108 uniquely promotes gain-of-function Shp2-induced GM-CSF hypersensitivity in a model of JMML. Blood 123: 2838-2842, 2014

35. Zhang E, Feng X, Liu F, Zhang P, Liang J and Tang X: Roles of $\mathrm{PI} 3 \mathrm{~K} / \mathrm{Akt}$ and $\mathrm{c}$-jun signaling pathways in human papillomavirus type 16 oncoprotein-induced HIF-1 $\alpha$, VEGF and IL-8 expression and in vitro angiogenesis in non-small cell lung cancer cells. Plos One 9: e103440, 2014.

36. Eräsalo H, Laavola M, Hämäläinen M, Leppänen T, Nieminen R and Moilanen E: PI3K Inhibitors LY294002 and IC87114 reduce inflammation in carrageenan-induced paw oedema and down-regulate inflammatory gene expression in activated macrophages. Basic Clin Pharmacol Toxicol 116: 53-61, 2015. 